\title{
OS FUNDAMENTOS DAS DESIGUALDADES SOCIAIS: PROPRIEDADE PRIVADA ENTRE ROUSSEAU E MARX
}

The Foundations of Social Inequalities: Private Property Between Rousseau and Marx

Bruno Gonçalves da Paixão *

Resumo: O presente artigo tem como objetivo discutir a relação entre o surgimento da propriedade privada e as desigualdades sociais a partir de uma articulação entre textos de dois pensadores: Jean-Jacques Rousseau e Karl Marx. O ponto em comum nessa articulação que o texto pretende demonstrar é o de que tanto as desigualdades quanto as classes sociais são fundadas pelo surgimento da propriedade privada, ou seja, tanto em Rousseau, que escreveu no século XVIII, quanto em Marx, que por sua vez é filho do século XIX, temos um mesmo elemento matricial que levou ao surgimento da relação de dominação do homem pelo o homem.

Palavras-chave: Propriedade privada, Classes sociais, Desigualdade social.

\begin{abstract}
The present article aims to discuss the relationship between the emergence of private property and social inequalities from an articulation between texts by two thinkers: Jean-Jacques Rousseau and Karl Marx. The common point in this articulation that the text supposedly attempts to demonstrate is that both inequalities and social classes are founded on the emergence of private property, i. e., both in Rousseau, who wrote in the 18th century, and in Marx, who in turn was born in the 19th century, we have the same matrix element that led to the emergence of the relationship of domination of man by man.
\end{abstract}

Keywords: Private property, Social classes, Social inequalities.

* Mestrando em Filosofia pela Universidade Estadual do Oeste do Paraná - Unioeste - brpja@ hotmail.com. Bolsista CNPQ.

\begin{tabular}{|c|c|c|c|c|c|}
\hline intuitio & $\begin{array}{c}\text { ISSN } \\
1983-4012\end{array}$ & Porto Alegre & Vol.8 $-\mathrm{N}^{\circ} .2$ & $\begin{array}{c}\text { Dezembro } \\
2015\end{array}$ & p.56-65 \\
\hline
\end{tabular}




\section{Introdução}

O texto que aqui se inicia tentará discutir uma possível aproximação, de forma prolegomenar, da tese sugerida por Rousseau sobre o surgimento das desigualdades entre os homens, relacionada com a teoria marxiana de surgimento das classes sociais (fato que funda a dominação de um grupo sobre o outro, logo, as desigualdades). O ponto em comum que o texto pretende demonstrar é o de que tanto as desigualdades quanto as classes sociais são fundadas pelo surgimento da propriedade privada, ou seja, tanto em Rousseau, que escreveu no século XVIII, quanto em Marx, que por sua vez é filho do século XIX, temos um mesmo elemento matricial que levou ao surgimento da relação de dominação do homem pelo o homem.

Essa observação introdutória, longe de tentar "marxianizar" Rousseau, ou ao contrário, "rousseauniar" Marx - e consequentemente incorrendo assim em equívocos interpretativos e históricos - é apenas o cerne de uma similitude que as pesquisas dos dois possibilitaram chegar. Mas que fique claro: a identificação de um momento relacional enquanto fundante dos males sociais entre os dois pensadores não os colocam de maneira alguma como partidários das mesmas interpretações sobre o desenvolvimento das relações sociais pautada na propriedade privada, muito menos às respostas de cada um para a solução do problema gerado por esse novo elemento surgido no mundo dos homens. Nesse sentido, procurar-se-á mostrar assim, como já assinala Marx em uma carta escrita em 1852, endereçada a Joseph Weydemeyer, que esse pensador não descobre o "ovo de Colombo", mas apenas adentra ainda mais nos temas já pincelados por alguns intelectuais, descobrindo novos caracteres que explicam melhor as múltiplas determinações de categorias complexas. Na referida carta, Marx vai falar que não cabe a ele "o mérito de ter descoberto nem a existência das classes [...] nem a sua luta entre si. Muito antes de mim, historiadores burgueses tinham exposto o desenvolvimento histórico desta luta das classes, e economistas burgueses a anatomia económica das mesmas"

\section{Propriedade privada: o fundante das desigualdades sociais}

A segunda parte do Discurso sobre a origem e os fundamentos da desigualdade entre os homens ${ }^{2}$, texto de onde se buscará subsídio para a presente empreitada, já de início, ou para ser mais exato, no primeiro parágrafo, nos apresenta a tese principal de Rousseau na referida obra: a de que a primeira pessoa

\footnotetext{
${ }^{1}$ MARX, Karl. Carta a Joseph Weydemeyer. In: Obras escolhidas. Tomo I. Edições Progresso Lisboa - Moscovo, 1982, p. 472.

${ }^{2}$ Sabemos que Rousseau discute a questão da propriedade privada também em outras obras sua como: $O$ Contrato Social e o Discurso sobre a origem da economia política. Mas para fins do que propomos por ora, ficaremos restritos - com todas as implicações que porventura possa ter o resultado do presente texto - única e exclusivamente à obra: Discurso sobre as origens e os fundamentos da desigualdade entre os homens.
}

\begin{tabular}{|c|c|c|c|c|c|}
\hline intuitio & $\begin{array}{c}\text { ISSN } \\
1983-4012\end{array}$ & Porto Alegre & Vol.8 $-\mathrm{N}^{\circ} .2$ & $\begin{array}{c}\text { Dezembro } \\
2015\end{array}$ & p.56-65 \\
\hline
\end{tabular}


que se apropriou de um espaço qualquer no mundo seria o responsável por fundar a sociedade civil, e consequentemente, fazer brotar das novas relações que se iniciariam todos os males sociais que assolam o homem pós-estado de natureza. Segundo este filósofo:

$\mathrm{O}$ verdadeiro fundador da sociedade civil foi o primeiro que, tendo cercado um terreno, lembrou-se de dizer isto é meu [...] Quantos crimes, guerras, assassínios, misérias e horrores não pouparia ao gênero humano aquele que arrancando as estacas ou enchendo o fosso, tivesse gritado a seus semelhantes: 'Defendei-vos de ouvir esse impostor; estareis perdidos se esquecerdes que os frutos são de todos e que a terra não pertence a ninguém!"”3.

$\mathrm{Na}$ citação acima o filósofo suíço afirma categoricamente que a apropriação privada foi o elemento matricial da sociedade civil, e que a não intervenção dos homens que perceberam essa decisão do "meu" sobre o que era até então de todos, defendendo o estado natural em que viviam, facilitou a reprodução de uma prática apropriadora individual, que gerou as misérias sociais que assolariam a humanidade. Mas esse relato, como é alertado pelo próprio autor, não ocorreu de forma abrupta, de uma hora para outra, mas ao contrário, se deu numa sucessão temporal incalculável e em forma de estágios. Assim, Rousseau "salta multidões de séculos", após falar algumas linhas sobre o homem não gregário e sua passagem das respostas animalescas às que possibilitavam atividades próprias, ou seja, embriões de práticas sociais propiciada pelas necessidades primárias, que na sua complexificação favoreceu o "esclarecimento do espírito e o aperfeiçoamento da indústria". A partir desse salto, recomeça esse autor do ponto em que o homem já possui conhecimento suficiente da natureza para produzir ferramentas como o machado, que por sua vez possibilitava o alcance de novas faculdades como construir habitações, após longo período de pousos em cavernas ou árvores. Diz ele: “A essa época se prende uma primeira revolução que determinou o estabelecimento e a distinção das famílias e que introduziu uma espécie de propriedade da qual nasceram talvez brigas e combates"6.

\section{Divisão sexual enquanto protoforma da divisão social do trabalho}

Na esteira dessa "primeira revolução", Rousseau vai apontar para o fato de que é a partir dessa nova situação, onde coabitam num mesmo espaço homem, mulher e filhos, propiciando "os primeiros

3 ROUSSEAU, Jean-Jacques. Discurso sobre a origem e os fundamentos da desigualdade entre os homens. In: $O s$ Pensadores. 2. ed. - São Paulo: Abril Cultural, 1979, p. 259.

${ }^{4}$ ROUSSEAU, Jean-Jacques. Discurso sobre a origem e os fundamentos da desigualdade entre os homens. In: $O s$ Pensadores. 2. ed. - São Paulo: Abril Cultural, 1979, p. 262.

${ }^{5}$ ROUSSEAU, Jean-Jacques. Discurso sobre a origem e os fundamentos da desigualdade entre os homens. In: Os Pensadores. 2. ed. - São Paulo: Abril Cultural, 1979, p. 262.

${ }^{6}$ ROUSSEAU, Jean-Jacques. Discurso sobre a origem e os fundamentos da desigualdade entre os homens. In: $O s$ Pensadores. 2. ed. - São Paulo: Abril Cultural, 1979, p. 262.

\begin{tabular}{|c|c|l|l|c|c|}
\hline intuitio & $\begin{array}{c}\text { ISSN } \\
1983-4012\end{array}$ & Porto Alegre & Vol.8 $-\mathrm{N}^{\circ} .2$ & $\begin{array}{c}\text { Dezembro } \\
2015\end{array}$ & p.56-65 \\
\hline
\end{tabular}


progressos do coração [...] e os mais doces sentimentos", que surge também as primeiras particularidades no modo de ser tanto do homem quanto no da mulher. É nesse momento que começa a formar a distinção clássica entre o que é atividade própria do sexo feminino e o que se configura enquanto prática laboral exclusivamente do sexo masculino. Nesse período "as mulheres tornaram mais sedentárias e acostumaram a tomar conta da cabana e dos filhos, enquanto os homens iam buscar a subsistência comum"8.

Esse apontamento de Rousseau, também é observado por Marx um século depois. Cabe nesse momento do texto, trazer o pensador alemão para a discussão. O que foi descrito acima pelo filósofo suíço é retomado (não necessariamente a partir de Rousseau) por Marx em várias obras em que ele trata da propriedade privada, como Manuscritos econômicos e Filosóficos (2004), A Ideologia Alemã (2007), Sobre a Questão Judaica (2010) e o Manifesto Comunista (1997), textos esses que compõe a literatura escolhida como referencial para tentar fazer essa ligação não unitária, mas de uma mesma investigação com resultados próximos, dos dois autores. Nesse sentido, como colocado na introdução, tentaremos agora empreender a difícil tarefa de falar dos dois de forma imbricada.

Retomando a afirmação acima, na qual apontamos o fato de Marx também falar da organização familiar como forma embrionária da sociedade, inclusive enquanto protoforma de relações que se desenvolveriam e se tornariam dimensões globalizantes de relações sociais mais complexas das sociabilidades futuras, o que chama a atenção num ponto comum entre a observação de Rousseau e Marx sobre a família é a divisão de tarefas por sexo, que será chamada posteriormente pelo autor alemão de “divisão social do trabalho". Para Marx essa divisão da qual já falara Rousseau, é a primeira forma da divisão social do trabalho, a divisão entre a atividade do homem e da mulher.

[...] na divisão natural do trabalho na família e na separação da sociedade em diversas famílias opostas umas às outras, estão dadas ao mesmo tempo a distribuição e, mais precisamente, a distribuição desigual, tanto quantitativa quanto qualitativamente, do trabalho e de seus produtos; portanto, está dada a propriedade, que já tem seu embrião, sua primeira forma, na família, onde a mulher e os filhos são escravos do homem. A escravidão na família, ainda latente e rústica, é a primeira propriedade ${ }^{9}$.

No excerto acima citado, o pensador alemão vai além de identificar a separação das atividades laborais entre os sexos opostos. Tomando de empréstimo uma categoria da economia clássica, a chamada divisão social do trabalho, descrevendo uma relação muito próxima do que Rousseau primeiramente trouxe à baila, não diferentemente do filósofo suíço, reconheceu nesse momento histórico das formações

\footnotetext{
${ }^{7}$ ROUSSEAU, Jean-Jacques. Discurso sobre a origem e os fundamentos da desigualdade entre os homens. In: $O s$ Pensadores. 2. ed. - São Paulo: Abril Cultural, 1979, p. 262.

${ }^{8}$ ROUSSEAU, Jean-Jacques. Discurso sobre a origem e os fundamentos da desigualdade entre os homens. In: $O s$ Pensadores. 2. ed. - São Paulo: Abril Cultural, 1979, p. 262.

${ }^{9}$ MARX, Karl. ENGELS, Friedrich. A Ideologia Alemã. São Paulo: Bomtempo, 2007, p. 36.
}

\begin{tabular}{|c|c|c|c|c|c|}
\hline intuitio & $\begin{array}{c}\text { ISSN } \\
1983-4012\end{array}$ & Porto Alegre & Vol.8 $-\mathrm{N}^{\circ} .2$ & $\begin{array}{c}\text { Dezembro } \\
2015\end{array}$ & p.56-65 \\
\hline
\end{tabular}


familiares, a forma embrionária da propriedade privada. Aqui se encontra um primeiro elo de uma teoria sobre o fundamento das desigualdades sociais tanto em Marx quanto em Rousseau.

A temática do que se passou a ser categorizado, décadas depois, como divisão social do trabalho ${ }^{10}$, é retomada por Rousseau em outros trechos da segunda parte dos Discursos, mas geralmente não é muito abordada pelos seus exegetas e estudiosos, passando muitas vezes despercebidos aos olhos do leitor, mas não por culpa de quem os lê, claro, mas pelo fato de que o autor suíço não usa tais termos para se referir à diferenciação dos tipos de artes, ou trabalhos. É importante enfatizar essa visualização de Rousseau de uma questão que seria amplamente estuda por economistas e filósofos séculos depois, pela sua atualidade.

Para o filósofo suíço, mesmo já iniciada a separação das tarefas de forma ainda não complexificada, nas suas formas mais simples, ou seja, "enquanto só se dedicaram a obras que um único homem podia criar, e a artes que não solicitavam o concurso de várias mãos [...]"11, os homens ainda gozaram da liberdade, desfrutavam de certa felicidade, mas no momento em que "um homem sentiu necessidade do socorro de outro, desde que se percebeu ser útil a um só contar com provisões para dois, desapareceu a igualdade, introduziu-se a propriedade $[\ldots]^{\prime \prime 12}$.

Essas passagens de Rousseau comprovam a afirmação de que mesmo não tratando tal temática pelas categorias que se conhecem hoje em dia, no texto em questão, esse filósofo já percebe os males na origem da divisão social do trabalho, que ao invés de propiciar um maior sentimento comunal, na realidade é um dos pressupostos para o acirramento das lutas entre os homens. Dessa relação surgirão várias artes e os homens passarão a depender uns dos outros, e logo essa dependência vai se afunilando e começa a separar uma minoria mais "produtiva" num determinado ramo, de outra, menos industriosa no seu campo específico. E aqui se visualiza o embrião da distinção entre ricos e pobres, chamada no século seguinte por Karl Marx de "oposições entre classes sociais".

\section{Apropriação privada do trabalho alheio}

Nesse momento, Rousseau traz à discussão a relação entre trabalho e propriedade privada, temática discutida exaustivamente por Marx em várias obras, desde textos da juventude até os da maturidade. Para o primeiro filósofo é inconcebível pensar a propriedade que não numa relação de "mão-

\footnotetext{
${ }^{10}$ Faz-se necessário alertar ao leitor que, ao utilizarmos uma categoria cunhada décadas depois dos escritos de Rousseau, e consolidada na literatura marxiana, não tem como objetivo levar ferramentas do futuro e colocar em textos anteriores para explicar uma relação já trabalhada, mas ainda não tão aprofundada a ponto de poder precisa-la enquanto uma categoria unanimemente reconhecida. Com essa nota esperamos evitar uma imagem anacrônica da categoria utilizada no texto.

${ }^{11}$ ROUSSEAU, Jean-Jacques. Discurso sobre a origem e os fundamentos da desigualdade entre os homens. In: $O s$ Pensadores. 2. ed. - São Paulo: Abril Cultural, 1979.

${ }^{12}$ ROUSSEAU, Jean-Jacques. Discurso sobre a origem e os fundamentos da desigualdade entre os homens. In: $O s$ Pensadores. 2. ed. - São Paulo: Abril Cultural, 1979.
}

\begin{tabular}{|c|c|c|c|c|c|}
\hline intuitio & $\begin{array}{c}\text { ISSN } \\
1983-4012\end{array}$ & Porto Alegre & Vol.8 $-\mathrm{N}^{\circ} .2$ & $\begin{array}{c}\text { Dezembro } \\
2015\end{array}$ & p.56-65 \\
\hline
\end{tabular}


de-obra, pois [...] para apropriar-se das coisas que não produziu, o homem nisso conseguiu pôr mais do que seu trabalho"13. Isso em essência é o entendimento de Marx da propriedade privada. Segundo Lessa,

a propriedade privada é esta relação social que faz com que o trabalho de um indivíduo possa ser apropriado por outro como sendo sua propriedade. A propriedade privada não são as coisas, mas a relação de exploração do homem pelo homem que se funda no poder econômico, isto é, o poder do que "se tem" passa a predominar sobre o que "se é"; é o predomínio do "ter" sobre o "ser" na conhecida expressão dos Manuscritos de 1844 de Karl Marx ${ }^{14}$.

Além de precisar o entendimento do filósofo alemão sobre a propriedade privada, nas franjas, a nosso ver, do entendimento de Rousseau, é assim como o primeiro dar ao trabalho o caráter fundante da relação descrita acima. Para Marx, "a propriedade privada é a base da divisão do trabalho [...] é o mesmo que dizer que o trabalho é a essência da propriedade privada". ${ }^{15}$ (MARX, 2004, p. 165). É dessa relação que a desigualdade se desenvolve: da apropriação privada do trabalho alheio, abrindo um fosso entre os que, mais propensos às atividades laborais (mais forte, mais habilidoso, mais esperto), se destacaram frente aos desprovidos de características superiores. Assim exemplifica Rousseau:

o mais forte realizava mais trabalho, o mais habilidoso tirava mais partido do seu, o mais engenhoso encontrava meios para abreviar a faina, o lavrador sentia mais necessidade de ferro, ou o ferreiro mais necessidade de trigo e, trabalhando igualmente, um ganhava muito enquanto outro tinha dificuldade em viver ${ }^{16}$.

Sem essa relação do trabalho com a apropriação privada do produto do trabalho alheio, seria, como apontado pelo próprio Rousseau, "impossível conceber a ideia de propriedade" ${ }^{17}$, ou seja, o trabalho aqui aparece enquanto elemento, assim como em Marx, essencial para o surgimento da propriedade, pois se não houvesse essa relação de dispor de mão de obra alheia, o homem não chegaria a um desenvolvimento suficiente para que a divisão entre ricos e pobres pudesse surgir. Seria, seguindo essa clareira aberta por Rousseau, impensável falar em ricos e pobres, num estágio onde nenhum homem pudesse subjugar o outro e organizar um sistema industrioso em que grupos de homens trabalhassem para produzir riqueza aos outros. Mas é do surgimento dessa relação que a propriedade privada surge e se desenvolve, trazendo consigo as desigualdades sociais e as instituições que as mantêm, fazendo florescer como flores espinhentas do idílico estado de natureza, a sociedade civil.

${ }^{13}$ ROUSSEAU, Jean-Jacques. Discurso sobre a origem e os fundamentos da desigualdade entre os homens. In: $O s$ Pensadores. 2. ed. - São Paulo: Abril Cultural, 1979, p. 266.

${ }^{14}$ LESSA, Sérgio. Ética, Política e Serviço Social. In: Revista Katalysis, UFSC: Florianópolis, 2005. V. 8, n. 2. 2005, p. 256-266.

${ }^{15}$ MARX, Karl. Manuscritos Econômico-Filosóficos. São Paulo: Boitempo. 2004, p. 165.

${ }^{16}$ ROUSSEAU, Jean-Jacques. Discurso sobre a origem e os fundamentos da desigualdade entre os homens. In: $O s$ Pensadores. 2. ed. - São Paulo: Abril Cultural, 1979, p. 266.

${ }^{17}$ ROUSSEAU, Jean-Jacques. Discurso sobre a origem e os fundamentos da desigualdade entre os homens. In: $O s$ Pensadores. 2. ed. - São Paulo: Abril Cultural, 1979, p. 266.

\begin{tabular}{|c|c|c|c|c|c|}
\hline intuitio & $\begin{array}{c}\text { ISSN } \\
1983-4012\end{array}$ & Porto Alegre & Vol.8 $-\mathrm{N}^{\mathrm{o}} .2$ & $\begin{array}{c}\text { Dezembro } \\
2015\end{array}$ & p.56-65 \\
\hline
\end{tabular}




\section{Luta entre ricos e pobres ou luta de classes? A necessidade mediadora de dominação das instituições políticas}

Mas, para se chegar à sociedade civil propriamente dita, a desigualdade teve que chegar a níveis extremos, onde a pilhagem, a desordem, os conflitos, motivados por uma ganância desenfreada, onde o império do amor próprio sobrepõe o amor-de-si, e onde o ser é subjugado pelo ter. A agudização da "concorrência e da rivalidade, oposição de interesses, e o desejo oculto de alcançar lucros às expensas de outrem [...] constituem o primeiro efeito da propriedade e o cortejo inseparável da desigualdade nascente" ${ }^{\prime 18}$. Aqui fica claro, a desigualdade caminha junto com a propriedade, enquanto existir a primeira, a segunda sempre será sua companheira. É desse turbilhão dos males nascente que surge a oposição entre ricos e pobres,

a dominação e a servidão" e a classe dominante, "os ricos, [...] nem bem experimentaram o prazer de dominar, logo desdenharam todos os outros, só pensaram e subjugar e dominar seus vizinhos, como aqueles lobos famintos que, uma vez comendo carne humana, recusam qualquer outro alimento e só querem devorar homens. [...] A sociedade nascente foi colocada no mais tremendo estado de guerra ${ }^{19}$.

Essa oposição conflituosa entre grupos sociais antagônicos foi futuramente chamada por Marx de lutas de classes, categoria central na teoria do pensador alemão que explica a relação de domínio de uma classe em detrimento da outra. Esse antagonismo bélico entre essas duas classes sociais, sempre segundo Marx, pode ser observado em toda a história assentada na propriedade privada, ou seja,

A história de toda a sociedade até aqui moveu-se em oposições de classes, as quais nas diversas épocas foram diversamente configuradas. [...] Mas fosse qual fosse a forma assumida, a exploração de uma parte da sociedade pela outra é um facto comum a todos os séculos passados ${ }^{20}$.

Com o desenvolvimento das desigualdades sociais, a oposição já não mais possível de ser contornada entre ricos e pobres, ou seja, a polarização entre classes atinge níveis já extremados, conflitantes, elevando o índice de injustiça e insegurança ao pico, onde a propriedade do rico, fruto da pilhagem, já não tinha tanta segurança assim, pois ao mesmo tempo em que apropriava indevidamente de terras alheias, era também pilhado pelos grupos de famintos que cresciam de forma progressiva. Como

${ }^{18}$ ROUSSEAU, Jean-Jacques. Discurso sobre a origem e os fundamentos da desigualdade entre os homens. In: $O s$ Pensadores. 2. ed. - São Paulo: Abril Cultural, 1979, p. 267.

${ }^{19}$ ROUSSEAU, Jean-Jacques. Discurso sobre a origem e os fundamentos da desigualdade entre os homens. In: $O s$ Pensadores. 2. ed. - São Paulo: Abril Cultural, 1979, p. 268.

${ }^{20}$ MARX, Karl. ENGELS, Friedrich. Manifesto do Partido Comunista. Editorial Avante! - Lisboa, 1997. p. 09.

\begin{tabular}{|c|c|l|l|c|c|}
\hline intuitio & $\begin{array}{c}\text { ISSN } \\
1983-4012\end{array}$ & Porto Alegre & Vol.8 $-\mathrm{N}^{\mathrm{o}} .2$ & $\begin{array}{c}\text { Dezembro } \\
2015\end{array}$ & p.56-65 \\
\hline
\end{tabular}


continuar numa sociabilidade onde nada era mais garantia de nada? Os ricos logo começaram a perceber que nesse caos social que a humanidade chegara, era mais prejudicial à sua rapina, pois o pobre não tinha nada a perder, já esses grupos dominantes, tinham toda a sua pilhagem sendo disputada por outros poderosos e pelos pobres.

Assim, numa sociabilidade, segundo Rousseau, já sem possibilidades de rompimento com a propriedade privada, ou seja, sem possibilidades de retornar ao seu estado de natureza, sendo rasgada pelos conflitos dos grupos sociais, é que os ricos, impelidos a resguardarem seus patrimônios, maquinam e concebem uma das mais importantes ideias no que concerne a "organização" social: as instituições políticas $^{21}$. A partir da relação descrita acima, surge a forma embrionária de todo aparato institucional que servirá de comitê privativo para as classes dominantes até o presente momento. Segundo Rousseau,

O rico, forçado pela necessidade [...] depois de expor a seus vizinhos o horror de uma situação que os armava, a todos, uns contra os outros [...] disse-lhes, 'instituamos regulamentos de justiça e de paz, aos quais todos sejam obrigados a conformar-se [...] submetendo igualmente a deveres mútuos o poderoso e o fraco [...] em lugar de voltar nossas forças contra nós mesmos, reunamo-nos num poder supremo que nos governe segundo sábias leis [...] Todos correram ao encontro de seus grilhões, crendo assegurar sua liberdade [...] Tal foi ou deveu ser a origem da sociedade e das leis, que deram novos entraves aos fracos e novas forças ao rico [...] fixaram para sempre a lei da propriedade e da desigualdade, fizeram de uma usurpação sagaz, um direito irrevogável ${ }^{22}$.

Para Rousseau a criação de aparatos institucionais foi pensada pelos grupos dominantes com o intuito de manter sua dominação sobre os pobres. Para isso, utilizou dos artifícios que dispunham para ter apoio dos próprios grupos que iriam ser submetidos e, sem grandes dificuldades, aglutinou forças o suficiente para instaurar a "prisão de mil janelas": a Política e o Direito. Sendo assim, o terreno para erigir a estrutura óssea de um poder usurpado, o Estado, já estava aplainado, e depois de criado esse poder supremo, que estaria acima de todos e supostamente para todos, voltar atrás já não era mais possível, pois, ao criarem esse poder mediador, regulador e garantidor da desigualdade social, sacramentaram também a matriz primária desse poder, a propriedade privada. Para o filósofo suíço, a partir desse momento, tais instituições não poderiam mais ser destruídas, era um caminho sem volta. O poder usurpado, fundado pela propriedade privada, era agora, um poder eterno, ineliminável da sociedade humana, passível apenas de aperfeiçoamento e reformas.

A criação dessa força estranha, que pairaria sobre a cabeça dos homens, é observada por Marx enquanto usurpação das forças reais do ser social. E essa assertiva do pensador alemão, segue-se após o mesmo citar trecho de Rousseau e creditar a este último, uma argumentação correta. Marx fala que

${ }^{21}$ O conceito "Pacto dos ricos" é a forma utilizada por Rousseau para evidenciar essa relação.

${ }^{22}$ ROUSSEAU, Jean-Jacques. Discurso sobre a origem e os fundamentos da desigualdade entre os homens. In: $O s$ Pensadores. 2. ed. - São Paulo: Abril Cultural, 1979, p. 268 a 271.

\begin{tabular}{|c|c|l|l|c|c|}
\hline intuitio & $\begin{array}{c}\text { ISSN } \\
1983-4012\end{array}$ & Porto Alegre & Vol.8- $\mathrm{N}^{\circ} .2$ & $\begin{array}{c}\text { Dezembro } \\
2015\end{array}$ & p.56-65 \\
\hline
\end{tabular}


Rousseau acertou na descrição da abstração do homem político, onde este lança: "é preciso que destitua $o$ homem de suas próprias forças para lhe dar outras que lhe sejam estranhas e das quais não possa fazer uso sem socorro alheio" ${ }^{23}$. Essa abstração do homem político não é nada mais nada menos do que a necessidade, imposta pela criação da propriedade privada, da emergência de um elemento mediador, que concentre em si as forças usurpadas (para muitos, outorgadas) dos homens. Mas para Marx, ao contrário de Rousseau, o homem poderia recuperar o domínio real sobre si e sobre sua história. Para isso, o caminho seria o revolucionamento da sociedade, possibilitando assim, a emancipação humana, e essa só estaria "plenamente realizada quando o homem individual real, [...] quando o homem tiver reconhecido e organizado suas "forces propres" [forças próprias] como forças sociais e, em consequência, não mais separar de si mesmo a força social na forma da força política"24.

Ao mesmo tempo em que aparece uma das raras evocações de Marx à obra de Rousseau, solta aos olhos o grande momento da diferenciação entre as considerações do filósofo suíço e do pensador alemão acerca da propriedade privada enquanto elemento fundante da luta entre grupos sociais antagônicos e não menos como matriz das instituições mediadoras desses conflitos, sempre a favor dos poderosos. Esse ponto de divergência concerne ao fato de que, se para Rousseau, como foi visto acima, não existe possibilidade alguma de eliminação da propriedade e dos seus frutos, como a política e o Estado, para Marx, essa superação não é só possível, mas necessária para a sobrevivência da humanidade. Segundo o estudioso alemão

A propriedade privada [...] é a expressão material-sensível da vida humana estranhada. Seu movimento - a produção e o consumo - é a manifestação (Offenbarung) sensível de toda produção até aqui, isto é, realização ou efetividade do homem. Religião, família, Estado, direito, moral, ciência, arte etc., são apenas formas particulares da produção e caem sob a sua lei geral. A supra-sunção (aufhebung) positiva da propriedade privada, enquanto apropriação da vida humana é, por conseguinte, a supra-sunção positiva de todo estranhamento (Entfremdung), portanto o retorno do homem da religião, família, Estado etc., à sua existência (Dasein) humana, isto é, social [Grifos nosso] ${ }^{25}$.

A citação acima, além de mostrar que o Estado, por exemplo, surge a partir da usurpação das forças sociais propiciado pela propriedade privada, assim como abordado (respeitando as limitações temporais) por Rousseau, afirma, agora diferentemente desse último, que a humanidade só conseguirá superar as desigualdades sociais e as instituições que a garante e reproduzem, pela supressão da propriedade privada, a raiz das desigualdades e das mantenedoras dessas. A partir desse ponto, em que após identificarem a propriedade privada enquanto fundamento primeiro, ontológico, dos males sociais, as respostas às possíveis saídas para a humanidade diante dos conflitos que as nega enquanto ser genérico

\footnotetext{
${ }^{23}$ MARX, Karl. Sobre a Questão Judaica. São Paulo: Boitempo, 2010, p. 53.

${ }^{24}$ MARX, Karl. Sobre a Questão Judaica. São Paulo: Boitempo, 2010, p. 54.

${ }^{25}$ MARX, Karl. Manuscritos Econômico-Filosóficos. São Paulo: Boitempo. 2004. p. 106.
}

\begin{tabular}{|c|c|c|c|c|c|}
\hline intuitio & $\begin{array}{c}\text { ISSN } \\
1983-4012\end{array}$ & Porto Alegre & Vol.8 $-\mathrm{N}^{\mathrm{o}} .2$ & $\begin{array}{c}\text { Dezembro } \\
2015\end{array}$ & p.56-65 \\
\hline
\end{tabular}


Os fundamentos das desigualdades sociais: propriedade privada entre Rousseau e Marx

tomam rumos totalmente antagônicos nas pesquisas de Rousseau e de Marx: para o primeiro, a saída será a reforma, o aperfeiçoamento e a educação, já para Marx, a possibilidade de superação das desigualdades sociais estaria na emancipação humana, mediada pelo ato de revolucionamento da sociedade.

\section{Considerações finais}

A exploração de categorias utilizadas por autores de séculos diferentes e que escreveram como filhos do seu tempo são sempre perigosas. Aproximar pensadores tão díspares como Marx e Rousseau, pode se tornar uma armadilha sem tamanho. Esperançoso que o texto acima não seja entendido como um trabalho que teve a pretensão de dizer que o pensador alemão teria sido um rousseauniano, que o estudou e desenvolveu sua teoria sobre propriedade privada diretamente a partir do filósofo suíço, nos arriscamos a caminhar nesse terreno pantanoso, pois entendemos que existem pontos nodais sobre a hipótese originária de uma relação social, categorizada enquanto propriedade privada, tanto em Rousseau quanto em Marx, e que o elemento mediador que poderia sustentar essa afirmação, estaria na obra de filosofia política de Hegel. Mas tal hipótese, por não fazer parte do objetivo a que nos propomos no presente trabalho, só poderia ser desenvolvida num futuro artigo.

\section{Referências}

LESSA, S. Ética, Política e Serviço Social. In: Revista Katalysis, Florianópolis, vol.8, n.2, 2005.

MARX, K. Carta a Joseph Weydemeyer. In: Obras escolhidas. Moscovo: Edições Progresso Lisboa, 1982. Manuscritos Econômico-Filosóficos. São Paulo: Boitempo, 2004. Sobre a Questão Judaica. São Paulo: Boitempo, 2010. ENGELS, F. A Ideologia Alemã. 2007. . Manifesto do Partido Comunista. Lisboa: Editorial Avante!, 1997.

ROUSSEAU, J-J. Discurso sobre a origem e os fundamentos da desigualdade entre os homens. In: Os Pensadores. 2.ed. São Paulo: Abril Cultural, 1979.

Data de Submissão: 28/09/2014

Data de Aprovação: 27/10/2015

\begin{tabular}{|c|c|c|c|c|c|}
\hline intuitio & $\begin{array}{c}\text { ISSN } \\
1983-4012\end{array}$ & Porto Alegre & Vol.8 $-\mathrm{N}^{\mathrm{o} .2}$ & $\begin{array}{c}\text { Dezembro } \\
2015\end{array}$ & p.56-65 \\
\hline
\end{tabular}

